\title{
Estas rimas son para ti: Exploring Learners Comprehension of Spanish Language Music Containing Dialectical Features
}

\author{
Avizia Yim Long and Megan Harsh
}

\begin{abstract}
This paper reports the findings of a study that examined native English-speaking learners' comprehension of Spanish language music containing Caribbean dialectal features. Twenty-one learners enrolled in 300- and 400-level Spanish content courses at a large, Midwestern public university in the US participated in this study. Each participant completed the following five tasks: (1) listening task, (2) listening task difficulty questionnaire, (3) vocabulary familiarity task, (4) Spanish language proficiency test, and (5) background questionnaire. The listening task contained short clips of Spanish language music, several of which contained dialectal features present in Caribbean speech and music. The results revealed that comprehension accuracy was very low on the listening task, and listening task items containing dialectal features were more difficult to comprehend for learners. Additionally, listening task scores were significantly correlated with knowledge of vocabulary items present in the music lyrics.
\end{abstract}

Keywords: dialectal features, listening comprehension, music, second language, Spanish

\section{Introduction}

Listening in a second language (L2) represents a multicomponential process that, as pointed out by Carrier (1999), involves two important dimensions. The first is a psycholinguistic dimension, of which previous research has focused on factors such as memory and speech rate in the comprehension of L2 speech (e.g., Call, 1985; Conrad, 1989). The second is a sociolinguistic dimension, of which previous research has examined factors such as topic familiarity (e.g., Schmidt-Rinehart, 1994), dialect familiarity (e.g., Schmidt, 2009), speaker accent or dialect (e.g., Eisenstein \& Berkowitz, 1981; Major, Fitzmaurice, Bunta, \& Balasubramanian, 2005; Wilcox, 1978), and individual characteristics of the listener (e.g., anxiety: Elkhafaifi, 2005; Yang, 1993; gender: Bacon, 1992; self-confidence: Fujita, 1985). Fewer studies have examined the impact of dialectal or regional features on learners' comprehension of L2 speech (e.g., Major et al., 2005; Schmidt, 2009), and, to the best of our knowledge, no study has investigated L2 learners' comprehension of music that contains dialectal features. In the case of classroom learners, music offers a readily available source of input that reflects a broad range of regional dialects and may demonstrate notable linguistic variation. The dialectal and regional 
variation that is present in music, however, may be difficult for learners to understand. Thus, including music in the L2 classroom may be challenging as it is unclear what aspects of music may impede learners' comprehension of it. The goal of the present study was to identify the difficulties students of Spanish encounter in their comprehension of music representing Caribbean Spanish dialects.

\section{Background}

\section{Sociolinguistic Competence in L2 Learning}

It has long been recognized that acquiring and using a L2 involves not only knowledge of grammar and discourse but also sociolinguistic aspects of the L2 (Canale \& Swain, 1980). Native speakers vary their language in response to a complex host of linguistic and social factors, several of which they may not even be aware. For example, how one greets their neighbor (e.g., hello, hey, hi, howdy, sup?, etc.) may vary as a function of the speech setting (e.g., on campus vs. in church), the interlocutor's age (e.g., child vs. elderly adult), dialectal or regional differences (e.g., New England vs. Southern US states), and so forth (Geeslin \& Long, 2014, pp. 3-4). What this means for the L2 learner is that he or she must learn to demonstrate sensitivity to the linguistic and social factors influencing the target language, both in perception and production.

Sociolinguistic competence is equally important for learners' comprehension of music in the L2. As mentioned in the Introduction, music often contains language features that demonstrate variation (i.e., have more than one "correct" way of being expressed). Music artists include such features in their music, either knowingly or unknowingly, to convey a particular message to their listeners. In the case of L2 learners, it is not likely, particularly at early stages of learning, that they "pick up" on the sociolinguistic aspects of that message. Therefore, being aware of and understanding the sociolinguistic variation present in music (much of which is also present in the everyday speech of native speakers) is an important component of $\mathrm{L} 2$ learning that the present study seeks to address.

\section{Previous Research on L2 Listening Comprehension}

Given the focus of our study on sociolinguistic aspects of L2 listening, in this section we concentrate our review of relevant literature on studies that have examined the sociolinguistic dimension of L2 listening.

Rubin (1994) notes five factors that contribute to the difficulties learners encounter when listening in the L2, two of which involve the sociolinguistic dimension of L2 listening comprehension and are of importance in the present study: listener characteristics and text characteristics. ${ }^{1}$ With regard to listener characteristics, previous research has investigated individual characteristics of the learner such as age (e.g., Seright, 1985), anxiety (e.g., Elkhafaifi, 2005; Yang, 1993), gender (e.g., Bacon, 1992), and proficiency in the L2 (see Rubin, 1994, for a review). This strand of research has shown that a host of individual characteristics indeed play a role in $\mathrm{L} 2$ listening comprehension, although that role may not be direct (e.g., gender; Bacon, 1992). However, the learner's proficiency in the L2

\footnotetext{
${ }^{1}$ The other factors outlined by Rubin (1994) in her review of L2 listening comprehension research included interlocutor characteristics, task characteristics, and process characteristics
} 
undoubtedly plays a role in L2 listening comprehension, to the extent that Rubin (1994) recommends that any study of L2 listening examine or assess the effect of L2 proficiency in some way. In the present study, we employ an independent measure of L2 proficiency and statistically examine the relationship between this learner characteristic and performance on the listening task in our study. Another learner characteristic we examine in detail is listening anxiety. Elkhafaifi (2005) reported a correlation between general foreign language anxiety and foreign language listening anxiety for classroom learners of Arabic, and his study also demonstrated an effect for both measures of anxiety on learners' comprehension of spoken Arabic. Following Elkhafaifi (2005), we also examine the effect of learners' listening anxiety to determine whether previous findings can be extended to learners of a distinct target language (i.e., Spanish).

Regarding text characteristics, text type has been shown to affect L2 listening comprehension (Rubin, 1994). For example, Shohamy and Ibar (1991) found that a news broadcast was most difficult for Israeli English as a foreign language (EFL) students to comprehend, followed by a short lecture then a dialogue. Another aspect of the text that has been examined in previous L2 listening comprehension research is the speaker's dialect or accent. An early study by Wilcox (1978) showed that learners of English comprehended the speech of speakers who shared their accent background (SingaporeanMalaysian) easier than native speakers of American English, Received Pronunciation (i.e., British English), or Australian English. Eisenstein and Berkowitz (1981) uncovered that learners of English found the standard variety of American English to be more intelligible than working-class (New York) English and foreign-accented English. Major et al. (2005) similarly found that learners of English found the standard variety of American English to be more comprehensible than regional (e.g., Southern English), ethnic (e.g., AfricanAmerican Vernacular English), and international (e.g., Indian English) varieties. In a study involving English-speaking learners of Spanish, Schmidt (2009) found that exposure to the Dominican variety of Spanish (after 3 weeks of time abroad in the Dominican Republic) led to improved comprehension of spoken Dominican speech by learners. Dominican Spanish, like many Caribbean dialects of Spanish, shares a host of variable, phonetic phenomena (e.g., /s/ aspiration: hasta "until" > ['ah.ta]; intervocalic /d/ deletion: helado "ice cream" > [e.'lao]) that have been suggested to pose challenges in listening comprehension for L2 listeners (Schmidt, 2009). These features, along with others, will be reviewed in detail in the Caribbean Dialectal Features section.

In addition to characteristics of the text and of the listener, it is widely accepted that the knowledge a learner brings to the task of listening also has an impact on L2 listening comprehension. This impact is positive, with previous research showing that background knowledge-be it cultural (e.g., Johnson, 1982), vocabulary (e.g., Johnson, 1982), or topic familiarity (e.g., Bernhardt, 1991; Hammadou, 1990; Schmidt-Rinehart, 1994)-aids comprehension of L2 speech. Schmidt-Rinehart (1994) further demonstrated that topic familiarity and L2 proficiency had an impact on L2 listening comprehension, although she found no interaction of the two variables. Given the importance of background knowledge demonstrated in previous research, the present study also investigates the effects of this factor on learners' comprehension of Spanish language music-specifically, vocabulary knowledge and topic familiarity (in the form of familiarity with music genres). 


\section{Previous Research on L2 Listening and Authentic Sources}

Few studies have examined the impact of authentic sources of oral input on L2 listening comprehension. Herron (1991) found that guided instruction (over a 15-week period) using unedited radio speech positively aided French learners' comprehension of unedited native speech. With regard to music, scholars have consistently pointed to its potential benefits as a tool for exposing classroom learners to authentic, target language input (e.g., Auger, 2003; Failoni, 1993; Garfinkel, 1972; Geeslin \& Long, 2014). For example, Garfinkel (1972) outlined a radio program, which included Spanish language music, and suggested that it could be used to improve learners' listening abilities. Garfinkel also indicated that popular music was included in the program with the hope of enhancing positive attitudes toward Spanish. In line with the goals of the present study, Geeslin and Long (2014) suggest that authentic sources of input such as music be incorporated into classroom instruction to expose learners to a wider variety of input. This input, as pointed out by Geeslin and Long, will demonstrate the variation that is inherent in the L2. What remains to be examined in detail is the extent to which dialectal features affect L2 listening comprehension, and what this means for incorporation of music containing dialectal features the L2 classroom.

\section{Caribbean Dialectal Features}

Caribbean Spanish is known for a wide range of dialectal features that distinguish it from other varieties of Spanish (e.g., Mexican Spanish, Argentine Spanish). As mentioned previously, there are a wide variety of variable, phonetic phenomena that may prove difficult to L2 learners in listening comprehension. The first is /s/ weakening, a term that encompasses elision (e.g., gatos "cats" > ['ga.to Ø]), aspiration (gatos > 'ga.toh]), and reduction of /s/ of any sort in coda position. Previous research has shown that, for L2 learners, accurate identification of /s/ aspiration as $s$ increases as experience with Spanish increases, and learners who have been exposed to /s/-weakening dialects are more accurate in identifying the aspirated variant (Schmidt, 2011). Additionally, learners produce weakened variants of /s/ at very low rates (Geeslin \& Gudmestad, 2011). Another phonetic phenomenon of relevance is intervocalic /d/ elision or deletion (e.g., hablado "spoken" > [ha.'ßlao]). Of note, both /s/ weakening and intervocalic /d/ elision are not restricted to Caribbean dialects (see Hualde, 2014). A third variable, phonetic phenomenon is related to the broader liquids sound category-namely, lateralization (e.g., puerta "door" $>$ ['pwel.ta]) and neutralization of /l/ and / $/$, for example, to [l] (e.g., arma "arms" and alma "soul" > ['al.ma]) or [y] (e.g., celda "cell" > ['cey. ða]; Guitart, 1997). A final phenomenon of note is velarization of [n] in word-final position (e.g. pan "bread" > ['pan]). These variable phonetic features, while not representative of an exhaustive list, are conditioned by a variety of linguistic and social factors in the speech of native Caribbean speakers. The task of the learner then is a complex one because not only is accurate perception of these segments necessary but appropriate comprehension and subsequent interpretation (not under study in the present paper) of speech containing these segments is also key. 


\section{The Present Study}

The purpose of this study was to investigate and analyze the comprehension of Spanish language music by classroom learners. As mentioned previously, Spanish music tends to have variable linguistic and regional features that may be difficult for L2 learners to understand. As a result, incorporating music into the L2 classroom may be challenging, as it is unclear what aspects of music-specifically, what dialectal features-may impede learners' comprehension of music lyrics. Therefore, this study is important because we aim to identify the difficulties students of Spanish encounter in comprehension when listening to Spanish language music from Caribbean Spanish dialects and address what this means for Spanish language learning and pedagogy more broadly. With these goals in mind, the specific research questions guiding this study are:

1. With what accuracy do learners of Spanish enrolled in 300- and 400-level courses comprehend Spanish language music lyrics containing Caribbean dialectal features?

2. What aspects of Spanish music (e.g., presence of specific dialectal features) predict accurate comprehension of music lyrics by learners of Spanish?

3. What learner characteristics (e.g., reported comprehensibility of lyrics, proficiency, reported study abroad experience, etc.) predict accurate comprehension of Spanish music lyrics?

\section{Methodology}

\section{Participants}

The participants of this study were 21 native English-speaking learners of Spanish enrolled in 300- or 400-level Spanish content courses (linguistics and/or literature) at a large, Midwestern public university. Thirteen of the participants were enrolled in 300-level courses and the other eight were enrolled in 400-level courses. Their average reported age was 19.85 years $(S D=1.42)$. Seven of the learners were male, and, the other 14 learners were female. Several of the participants reported knowledge of additional languages, such as Portuguese $(n=5)$, French $(n=1)$, German $(n=1)$, and Mandarin $(n=1)$. Nearly half of the learners also reported spending time abroad in a Spanish-speaking country $(n=9 ; M=$ 0.56 years, $S D=0.58$ years, Min. $=7$ weeks, Max. $=2$ years ).

Pertinent to the present investigation, nearly all of the learners reported listening to Spanish music, either weekly $(n=6)$, monthly $(n=5)$, or a few times a year $(n=8)$. Only two of the participants reported never listening to Spanish music. The types of Spanish music participants reported listening to included alternative, bachata $(n=1)$, cumbia $(n=$ $1)$, folk/traditional $(n=2)$, hip hop $(n=2)$, mariachi $(n=1)$, pop $(n=8)$, rap $(n=2)$, reggaeton $(n=5)$, rock $(n=8)$, and salsa $(n=1)$.

\section{Materials}

The experimental procedure for this study was largely motivated by Schmidt (2009)—who also examined listening comprehension of dialectal features by L2 Spanish learners-and consisted of the following five tasks: (1) listening task, (2) listening task difficulty questionnaire, (3) vocabulary familiarity task, (4) Spanish language proficiency test, and 
(5) background questionnaire.

Listening task. The listening task consisted of 43 short clips of music, five of which were practice items (and not included in data analysis). Each clip contained eight total words or less to control for phrase length of each task item. For this task, participants were instructed to listen to each music clip, write down word-for-word what they heard in Spanish, and then translate it into English (see Figure 1). Participants had to listen to each music clip two times before the task allowed them to advance to the next item. Following the translation into English, participants were instructed to rate the comprehensibility (i.e., how easy to understand) of each music clip on a Likert scale ranging from 1 (easy) to 5 (difficult). The listening task was self-paced, and participants recorded all of their responses on a separate answer sheet provided by the researchers (see Appendix A). Additionally, the clips included in the listening task (including practice clips) were organized by artist into four distinct sections. Each section began with a $10 \mathrm{~s}$ clip from a song by the music artist "featured" in that section. This aspect of the design of the task was carried out so that participants would have the opportunity to familiarize themselves with the genre of each musical artist before listening to the clips of that artist for comprehension, thereby addressing the potential influence of music genre on listening comprehension.

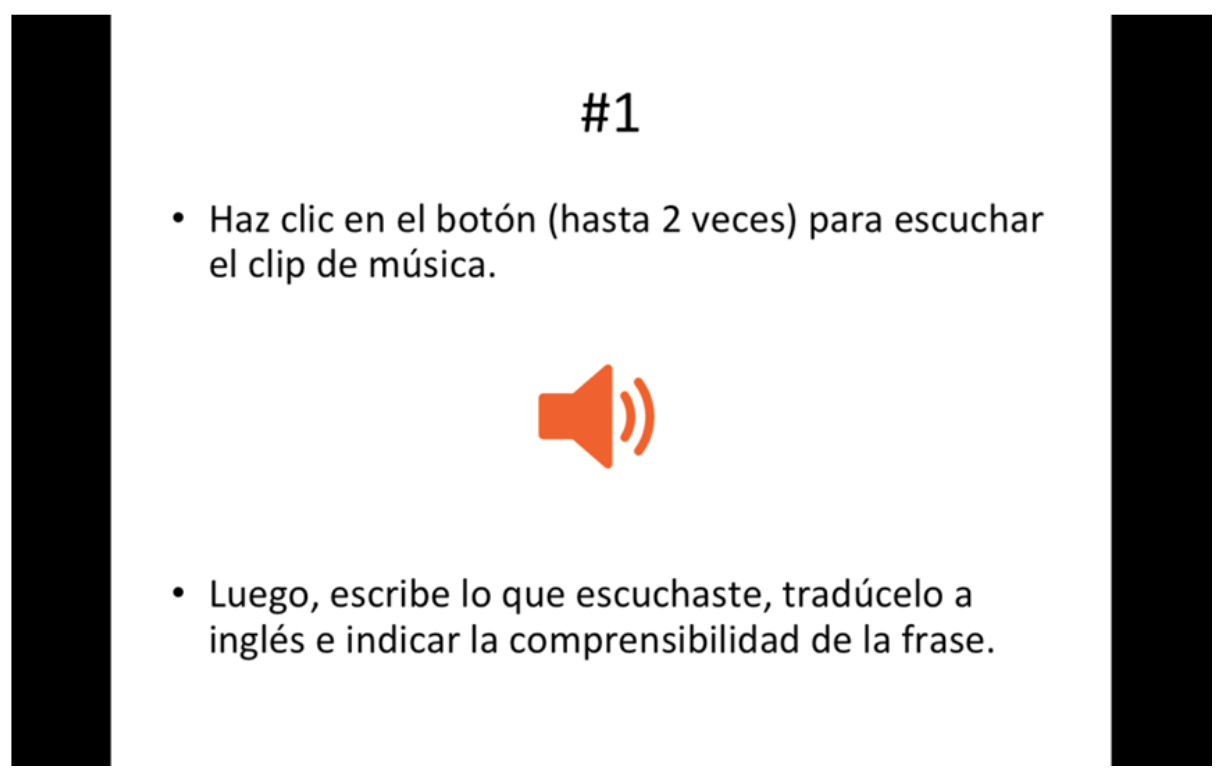

Figure 1. Screenshot of listening task item

With regard to the music included in the listening task, four distinct artists were featured in the listening task: Calle 13, Elvis Crespo, Buena Vista Social Club, and Gente de Zona. These artists were selected because they are representative of three popular Caribbean music genres-merengue, reggaeton, and son. Table 1 outlines the artists and 
genres corresponding to each set of items on the listening task, as well as the song titles from which music clips were sampled and the dialectal features present in those clips (a more specific list of which features presented in each individual item of the task can be found in Table 3 of the Results section). There were also a number of items from each artist that did not contain the specific dialectal features under study but were included as filler items (marked as "none" in the dialectal features column of Table 1). Finally, three of the items on the listening task contained two dialectal features: one item by Buena Vista Social Club, one by Elvis Crespo, and one by Gente de Zona.

\section{Table 1. Overview of listening task items and examples}

\begin{tabular}{|c|c|c|c|c|}
\hline $\begin{array}{l}\text { Listening } \\
\text { task items }\end{array}$ & $\begin{array}{c}\text { Artist } \\
\text { (genre) }\end{array}$ & $\begin{array}{c}\text { Song titles (item } \\
\text { number) }\end{array}$ & $\begin{array}{l}\text { Dialectal features } \\
\text { ( } n \text { items) }\end{array}$ & Example item \\
\hline $1-8$ & $\begin{array}{c}\text { Calle } 13 \\
\text { (reggaeton) }\end{array}$ & $\begin{array}{c}\text { Persiguido (items 1, } \\
\text { 4, 5, 7, and 8) } \\
\text { Adentro (item 2) } \\
\text { Muerte en Hawaii } \\
\text { (items } 3 \text { and 6) }\end{array}$ & $\begin{array}{l}\text { para reduction (2) } \\
\text { /d/ elision (2) } \\
\text { /s/ reduction (3) } \\
\text { none (1) }\end{array}$ & $\begin{array}{c}\text { Item } 2 \\
\text { Estas rimas son pa' ti } \\
\text { "These rhymes are for } \\
\text { you" (para reduction) }\end{array}$ \\
\hline $9-16$ & $\begin{array}{l}\text { Elvis Crespo } \\
\text { (merengue) }\end{array}$ & $\begin{array}{c}\text { Pegaito suavecito } \\
\text { (items } 9,10,12,13, \\
15, \text { and } 16^{*} \text { ) } \\
\text { Conmigo contigo } \\
\text { (items } 11 \text { and } 14 \text { ) }\end{array}$ & $\begin{array}{l}\text { para reduction (1) } \\
/ \mathrm{d} / \text { elision (2) } \\
\text { /s/ reduction (3) } \\
\text { para reduction }+/ \mathrm{s} / \\
\text { reduction (1) } \\
\text { lateralization (1) }\end{array}$ & $\begin{array}{c}\text { Item } 13 \\
\text { Que tú mueves tu cuelpo } \\
\text { "That you move your } \\
\text { body" (lateralization in } \\
\text { cuerpo) }\end{array}$ \\
\hline $17-26$ & $\begin{array}{l}\text { Buena Vista } \\
\text { Social Club } \\
\text { (son) }\end{array}$ & $\begin{array}{c}\text { El carretero; De } \\
\text { camino (items } 17 \text { and } \\
18^{*} \text { ) } \\
\text { El cuarto (items } 25 \\
\text { and 26) } \\
\text { Guateque campesino } \\
\text { (items } 23 \text { and 24) } \\
\text { Candela (items 19, } \\
\text { 20, 21, and 22) }\end{array}$ & $\begin{array}{l}\text { para reduction (2) } \\
\text { /d/ elision (2) } \\
\text { /s/ reduction (1) } \\
\text { /d/ elision }+/ \mathrm{s} / \\
\text { reduction (1) } \\
\text { lateralization (1) } \\
\text { none (3) }\end{array}$ & $\begin{array}{c}\text { Item } 26 \\
\text { Yo trabajo sin reposo "I } \\
\text { work without rest" } \\
\text { (none) }\end{array}$ \\
\hline $27-38$ & $\begin{array}{c}\text { Gente de Zona } \\
\text { (reggaeton) }\end{array}$ & $\begin{array}{c}\text { Habanero (items 34*, } \\
\text { 36, 37, and 38) } \\
\text { El cabaret (items } 27 \\
\text { and 28) } \\
\text { Ella tiene el pelo } \\
\text { largo (items 29, 30, } \\
31,32,33 \text {, and 35) }\end{array}$ & $\begin{array}{l}\text { para reduction (1) } \\
/ \mathrm{d} / \text { elision }(2) \\
\text { /s/ reduction (3) } \\
\text { para reduction }+/ \mathrm{s} / \\
\text { reduction (1) } \\
\text { none (5) }\end{array}$ & $\begin{array}{c}\text { Item } 32 \\
\text { Ella te dice cuando está } \\
\text { enamoraa "She tells you } \\
\text { when she's in love" (/d/ } \\
\text { elision in enamorada) }\end{array}$ \\
\hline
\end{tabular}

Note. ${ }^{*}$ indicates an item that contained two dialectal features.

Listening task difficulty questionnaire. Following completion of the listening task, participants completed a listening task difficulty questionnaire. This questionnaire asked them to rate, on a Likert scale from 1 (easy) to 5 (difficult), how difficult they thought 
the listening task was and how long they think it took them to complete it. These two measures of perceived task difficulty were incorporated into the design of the study following Baralt (2010) as two independent ways of assessing potential difficulty associated with completing the listening task. At the end of this questionnaire, participants were also asked if they recognized any of the songs, artists, or dialectal features present in the listening task.

Vocabulary familiarity task. Participants were instructed to rate their familiarity with 20 words found in the music clips included on the listening task. Ratings were conducted using the following scale: $1=$ I have never seen or heard the word before; $2=I$ have heard the word but do not know its meaning; 3 = I know the meaning and can provide an English equivalent. Space was provided on the task sheet to write the English equivalent of words for which "3" was selected. The vocabulary task did not include every word from each music clip included on the listening task, only vocabulary for which the researchers judged to be potentially challenging for the learner group targeted in the present study. The words included on the vocabulary task, along with their English translations, can be found in Appendix B.

Proficiency test. Participants completed a proficiency test to see if their proficiency level was comparable to other participants at their course level. The test consisted of 25 multiple choice items that fill in blanks of a short story. The story, about a Hispanic female college student, contained familiar vocabulary for students. The proficiency test focused on grammatical structures that are known to be challenging for learners of Spanish (e.g., use of ser vs. estar, preterit vs. imperfect, indicative vs. subjunctive; Geeslin, 2014). Each blank contained three response options. The first two sentences of the proficiency test are presented as a sample in Appendix C.

Background questionnaire. The background questionnaire elicited basic demographic information from each participant, as well as information about previous Spanish language study (in a classroom setting and abroad), use of Spanish outside of the classroom, knowledge of other languages, perceptions of Spanish language ability, and experience with Spanish language music both inside and outside of the classroom. The background questionnaire also included a foreign language listening anxiety questionnaire, adapted from Elkhafaifi (2005), to examine the relationship between learners' listening anxiety and performance on the listening task. Participants were instructed to rate the extent to which they agreed or disagreed with the 18 statements provided $(1=$ strongly disagree, 5 = strongly agree). Items from the listening anxiety portion of the background questionnaire can be found in Appendix A.

\section{Procedure}

Before participating in the study, learners reviewed and provided consent for participation. Participants then completed each task in the order described previously. Participants took 30-40 minutes to complete the listening task and 15-20 minutes to complete the other four tasks. All tasks were completed outside of class in a quiet laboratory. To complete the listening task, participants were instructed to use the headphones provided with the laboratory computer and write their answers on an answer sheet provided by the researchers (see Appendix B). The remaining tasks were also completed on paper and 
provided by the researchers only after completing the listening task.

\section{Data Coding and Analysis}

For the listening task, following Schmidt (2009), participants were given 1 point for each item if their English translation of the Spanish music clip was correct (i.e., comprehension of the entire phrase). Partial credit was not assigned, and participants did not receive points for providing the correct Spanish lyric without also correctly providing its corresponding English translation. In determining what was considered "correct" in the English translations, we focused on content words (e.g., nouns, verbs) more than words that carry less meaning (e.g., articles). For example, for tengo una vida loca, if a participant translated this phrase as "I have the crazy life" instead of "I have a crazy life," they were still given 1 point for comprehension of the phrase.

For the vocabulary task, participants' responses were coded as rated ("1," " 2 ," or " 3 "). However, if participants rated their familiarity of a vocabulary item as " 3 " (I know the meaning and can provide an English equivalent) but provided an incorrect English equivalent, their rating was changed to a "2" (I have heard the word but do not know its meaning).

For the proficiency test, participants' responses were coded as correct or incorrect based on the multiple choice option selected. No partial credit was given for this task, as each question contained only one correct answer. Scores were determined by adding the number of correct responses, with a maximum score of 25 points.

Finally, for the listening anxiety section of the background questionnaire, participants' ratings were converted into points to yield a listening anxiety score. The points assigned for ratings of positively worded statements corresponded to the number of rating itself (e.g., a rating of 5 yielded 5 points), whereas points assigned for ratings of negatively worded statements were reverse coded (e.g., a rating of 5 yielded 1 point, 4 yielded 2 points, etc.). Using this method, the minimum possible score was 18, corresponding to low listening anxiety, and the maximum possible score was 90, corresponding to high listening anxiety.

To answer the first research question, we (a) examined the frequency of accurate and inaccurate responses on the listening task by participant as well as by participant course level (300- or 400-level); (b) analyzed the frequency of accurate responses on the listening task by item to identify the dialectal features that appear to be more challenging to the learners in their comprehension of the Spanish music lyrics; and (c) performed correlation analyses to examine the relationship between accuracy on the listening task and learners' self-reported ratings of comprehensibility, task difficulty, and vocabulary knowledge. To address the second and third research questions, we conducted a binary logistic regression analysis to identify the factors (related to the music included in the task and to the learners) predicting accurate comprehension of Spanish music lyrics. 


\section{Results}

\section{Listening Comprehension Accuracy}

Across all participants, the average rate of accuracy for comprehension of listening task items was very low, at $10.9 \%$ (approximately $4 / 38$ items; $S D=3.96$ ). There was, however, a wide range of variability in performance, with a minimum observed score of 1 (2.6\%) and a maximum score of 18 (47.4\%). Nevertheless, from Figure 2 it is evident that most participants $(n=16)$ scored well under 5 points on the listening task.

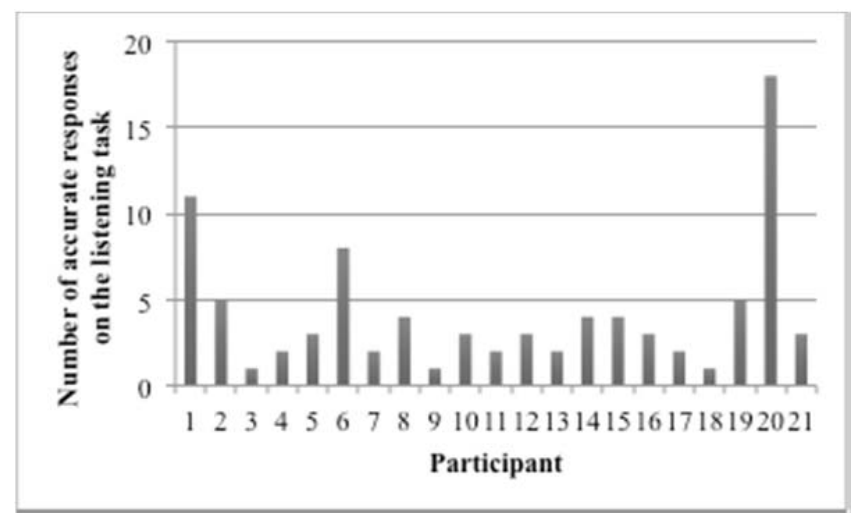

Figure 2. Distribution of Accurate Responses on the Listening Task by Participant

Table 2 presents the distribution of accurate and inaccurate responses on the listening task by participant course level (either 300- or 400-level).

Table 2. Accuracy on the Listening Task by Participant Course Level

\begin{tabular}{lcccc}
\hline Course level & \multicolumn{2}{c}{ Inaccurate responses } & \multicolumn{2}{c}{ Accurate responses } \\
& $N$ & $\%$ & $N$ & $\%$ \\
\hline 300 & 462 & 93.5 & 32 & 6.5 \\
400 & 248 & 81.6 & 56 & 18.4 \\
\hline
\end{tabular}

The findings in Table 2 reveal that accuracy on the listening task was higher for 400 - than for 300-level learners. A one-way ANOVA revealed that this difference was statistically significant, $F(1,796)=28.26, p<.001$.

Before turning to our examination of factors related to successful comprehension of the Spanish language music lyrics tested in this study, an analysis of accuracy by item is outlined. Table 3 provides accuracy rates on the listening task by item and course level of the participants. 
Table 3. Accuracy on the Listening Task by Item and Participant Course Level

\begin{tabular}{|c|c|c|c|c|c|}
\hline \multirow[t]{3}{*}{ Item } & \multirow[t]{3}{*}{ Dialectal features present } & \multicolumn{4}{|c|}{ Accuracy } \\
\hline & & \multicolumn{2}{|c|}{$\begin{array}{c}\text { 300-level } \\
(n=13)\end{array}$} & \multicolumn{2}{|c|}{$\begin{array}{c}\text { 400-level } \\
(n=8)\end{array}$} \\
\hline & & $N$ & $\%$ & $N$ & $\%$ \\
\hline 1 & para reduction & 0 & 0 & 3 & 37.5 \\
\hline 2 & para reduction & 0 & 0 & 2 & 25.0 \\
\hline 3 & /d/ elision & 0 & 0 & 3 & 37.5 \\
\hline 4 & /s/ reduction & 0 & 0 & 2 & 25.0 \\
\hline 5 & None (filler item) & 0 & 0 & 0 & 0 \\
\hline 6 & /d/ elision & 0 & 0 & 1 & 12.5 \\
\hline 7 & /s/ reduction & 2 & 15.4 & 2 & 25.0 \\
\hline 8 & /s/ reduction & 2 & 15.4 & 3 & 37.5 \\
\hline 9 & para reduction & 0 & 0 & 1 & 12.5 \\
\hline 10 & /s/ reduction & 0 & 0 & 0 & 0 \\
\hline 11 & /s/ reduction & 0 & 0 & 0 & 0 \\
\hline 12 & /d/ elision & 0 & 0 & 2 & 25.0 \\
\hline 13 & Lateralization & 5 & 38.5 & 6 & 75.0 \\
\hline 14 & /d/ elision & 0 & 0 & 0 & 0 \\
\hline 15 & /s/ reduction & 3 & 23.1 & 2 & 25.0 \\
\hline 16 & $\begin{array}{l}\text { para reduction } \\
\text { /s/ reduction }\end{array}$ & 2 & 15.4 & 6 & 75.0 \\
\hline 17 & None (filler item) & 0 & 0 & 3 & 37.5 \\
\hline 18 & $\begin{array}{l}\text { /d/ elision } \\
\text { /s/ reduction }\end{array}$ & 0 & 0 & 0 & 0 \\
\hline 19 & /s/ reduction & 0 & 0 & 0 & 0 \\
\hline 20 & para reduction & 0 & 0 & 0 & 0 \\
\hline 21 & Lateralization & 0 & 0 & 0 & 0 \\
\hline 22 & None (filler item) & 0 & 0 & 0 & 0 \\
\hline
\end{tabular}




\begin{tabular}{|c|c|c|c|c|c|}
\hline Item & Dialectal features present & & Acc & cy & \\
\hline 23 & /d/ elision & 0 & 0 & 1 & 12.5 \\
\hline 24 & /d/ elision & 0 & 0 & 0 & 0 \\
\hline 25 & para reduction & 1 & 7.7 & 1 & 12.5 \\
\hline 26 & None (filler item) & 4 & 30.8 & 4 & 50.0 \\
\hline 27 & None (filler item) & 0 & 0 & 0 & 0 \\
\hline 28 & para reduction & 0 & 0 & 1 & 12.5 \\
\hline 29 & /s/ reduction & 0 & 0 & 0 & 0 \\
\hline 30 & /d/ elision & 0 & 0 & 1 & 12.5 \\
\hline 31 & /s/ reduction & 0 & 0 & 0 & 0 \\
\hline 32 & /d/ elision & 0 & 0 & 0 & 0 \\
\hline 33 & None (filler item) & 0 & 0 & 3 & 37.5 \\
\hline 34 & $\begin{array}{l}\text { para reduction } \\
\text { /s / reduction }\end{array}$ & 0 & 0 & 1 & 12.5 \\
\hline 35 & None (filler item) & 0 & 0 & 0 & 0 \\
\hline 36 & None (filler item) & 0 & 0 & 0 & 0 \\
\hline 37 & /s/ reduction & 0 & 0 & 0 & 0 \\
\hline 38 & None (filler item) & 13 & 100 & 8 & 100 \\
\hline
\end{tabular}

There are several trends from Table 3 that are worth pointing out. First, the 400-level learners outperform the 300-level learners on each item of the listening task. Second, it is not always the case that learners (regardless of course level) demonstrate higher accuracy rates for items that do not contain dialectal features. As can be seen in Table 3, there are several filler items for which learners did not demonstrate accurate comprehension of the music lyrics (e.g., Items 5, 22, 27, 35, and 36). However, there are two filler items for which 400-level learners outperform the 300-level learners (i.e., Items 17 and 26), in addition to one filler item that all learners (irrespective of course level) comprehended accurately (i.e., Item 38). This finding will be addressed further in the Discussion section. Third, all learners demonstrate greater comprehension of music lyrics containing reduction of para to $p a^{\prime}$, in general, than of lyrics containing /d/ elision and/or /s/. There are a few exceptions to this trend (see Items 7, 8, and 20), which suggest that other factors may be in play. Finally, the two task items that contained lateralization demonstrated divergent accuracy patterns: 
Learners performed better on Item 13 (38.5\% accuracy for 300-level; 75.0\% accuracy for 400-level) than on Item 21 (0\% accuracy for 300- and 400-level).

\section{The Role of Comprehensibility, Vocabulary Knowledge, and Task Difficulty in the Comprehension of Spanish Music}

Recall that all participants rated the comprehensibility (i.e., ease of understanding) of each item in the listening task, as well as completed a vocabulary knowledge task and task difficulty questionnaire. With regard to comprehensibility, the average rating across participants was $3.89(S D=.42 ; N=20),{ }^{2}$ which corresponds most closely to the somewhat difficult point of the comprehensibility rating scale. A Spearman's rank-order correlation analysis revealed a nonsignificant, negative correlation between participants' listening task scores and comprehensibility ratings, $r_{s}=-.42, p=.069$.

Regarding vocabulary knowledge, the average rating across participants was 2.15 $(S D=.37)$, corresponding to the I have heard this word before, but I don't know what it means point of the rating portion of the vocabulary knowledge task. In fact, an average rating of 2.00 or lower was observed for six participants only, and the lowest average rating was 1.47. These findings suggest that most of the words were familiar and/or known to participants. There was a significant, positive correlation between participants' listening task scores and vocabulary knowledge ratings, $r_{s}=.62, p=.003$. In other words, higher ratings were significantly related to higher scores on the listening task.

With regard to task difficulty, the average rating across participants was 4.81 (SD = .51), which falls closer to the difficult point of the rating scale. Interestingly, all but three participants rated the task at 5 (difficult); two participants rated the difficulty of the task at 4 (somewhat difficult) and one participant rated it at 3 (neither difficult nor easy). There was a nonsignificant, negative correlation between participants' listening task scores and task difficulty ratings, $r_{s}=-.13, p=.567$.

\section{Factors Predicting Accurate Comprehension of Spanish Music}

To identify those factors that predict accurate comprehension of items included on the Spanish music listening task, a binary logistic regression was conducted with accuracy $(1=$ correct, 0 = incorrect) as the dependent variable. The predictor variables included in the regression model were as follows: dialectal feature(s) present, comprehensibility of the music lyrics, proficiency score, frequency of listening to Spanish music, and whether or not the participant reported studying abroad in a Spanish-speaking country. ${ }^{3}$ Table 4 outlines the results of the binary logistic regression model.

\section{Table 4. Coefficients of the model predicting whether learners accurately comprehended the Spanish music lyric}

\footnotetext{
${ }^{2}$ One participant misunderstood the listening task answer sheet. Consequently, her ratings were not included in this analysis.

${ }^{3}$ To determine which predictor variables to include in the binary logistic regression analysis, we examined best-fit $\left(\chi^{2}\right)$ statistics for each predictor variable. The following predictor variables were not included in the binary logistic regression analysis because they did not significantly improve the model (i.e., $p>.05$ ): music artist, music genre, and listening anxiety.
} 


\begin{tabular}{|c|c|c|c|c|c|}
\hline \multirow{2}{*}{$\begin{array}{l}\text { Variables included } \\
\text { in model }\end{array}$} & \multirow[t]{2}{*}{$B$} & \multirow[t]{2}{*}{$p$} & \multirow[t]{2}{*}{ Odds } & \multicolumn{2}{|c|}{ 95\% confidence interval } \\
\hline & & & & Lower & Upper \\
\hline Constant & -1.60 & .107 & 0.20 & - & - \\
\hline \multicolumn{6}{|l|}{$\begin{array}{l}\text { Comprehensibility } \\
\text { (reference = easy) }\end{array}$} \\
\hline Difficult & -3.72 & $<.001$ & 0.02 & 0.01 & 0.05 \\
\hline $\begin{array}{l}\text { Neither easy nor } \\
\text { difficult }\end{array}$ & -1.63 & $<.001$ & 0.20 & 0.08 & 0.49 \\
\hline $\begin{array}{l}\text { Dialectal features } \\
\text { (reference }=\text { no) }\end{array}$ & -0.97 & .003 & 0.38 & 0.20 & 0.72 \\
\hline Proficiency score & 0.05 & .419 & 1.05 & 0.94 & 1.17 \\
\hline $\begin{array}{l}\text { Study abroad } \\
(\text { reference = no) }\end{array}$ & 0.89 & .018 & 2.43 & 1.16 & 5.07 \\
\hline
\end{tabular}

\begin{tabular}{|c|c|c|c|c|c|}
\hline \multicolumn{6}{|l|}{$\begin{array}{l}\text { Music listening } \\
\text { (reference = few } \\
\text { times a year) }\end{array}$} \\
\hline Monthly & 0.98 & .021 & 2.66 & 1.16 & 6.14 \\
\hline Never & 1.48 & .033 & 4.38 & 1.13 & 17.05 \\
\hline Weekly & 1.38 & $<.001$ & 3.98 & 1.85 & 8.56 \\
\hline
\end{tabular}

With the exception of participant proficiency score, all of the predictor variables included in the model significantly predicted accurate responses on the listening task. With regard to comprehensibility, participants were 0.02 times less likely to demonstrate accurate comprehension of the Spanish music lyric when they marked the lyric as difficult to understand rather than as easy to understand. Participants were similarly 0.38 times less likely to demonstrate accurate comprehension when the lyric contained dialectal features than when no such features were present. Learners with study abroad experience were 2.43 times more likely to demonstrate accurate comprehension on the listening task than those who didn't report such experience. Finally, learners who reported listening to Spanish language music weekly or monthly were 3.98 and 2.66 times more likely, respectively, to demonstrate accurate comprehension than those who reported only listening to Spanish music a few times a year. However, participants who reported never listening to Spanish music were also more likely to demonstrate accurate comprehension than those who only listen to it a few times a year. This finding, although seemingly contradictory, may suggest that a different factor may be at play or interacting with reported frequency of listening to Spanish language music.

\section{Discussion}

As a reminder, this study was guided by three research questions (see The Present Study section). In response to the first research question, our findings showed that both 300 - and 400-level learners demonstrated low comprehension of Spanish language music containing Caribbean dialectal features. Specifically, the average accuracy rate for comprehension of 
the listening task items was only $10.9 \%$, representing approximately four out of the 38 items total. As seen in Figure 2, the majority of learners (16 of 21 participants), from both 300- and 400- levels, scored lower than 5 on the listening task. The low comprehension scores observed across learner course level on the listening task suggests that listening to music in Spanish is difficult regardless of the dialectal features that are present or the genre of music that is played. In fact, the items with dialectal features were not always the most difficult for learners to comprehend. Furthermore, there were several filler items that learners, regardless of course level, failed to comprehend. Taken together, it may be that music represents one of the more difficult sources of input in terms of L2 listening comprehension. Nevertheless, several factors, in addition to dialectal features, should be taken into consideration in the examination of L2 comprehension of music.

In terms of the dialectal features present in the listening task items, this study showed that, in general, learners comprehended items demonstrating para reduction more than items containing other dialectal features (e.g., /d/ elision, /s/ aspiration). This finding could be attributed to the frequency with which speakers of Spanish, and across dialectal or regional varieties of Spanish, employ para reduction in speech (Diaz-Campos, Fafulas, \& Gradoville 2012). However, the few exceptions to this observation, again, suggest that additional factors are at play in the comprehension music lyrics containing dialectal features.

Other factors examined in relation to the accuracy of learners' responses on the listening task were the reported comprehensibility of the music lyrics and task difficulty. Though expected to play a more significant role in learners' performance, both of these factors proved to be insignificantly correlated with accuracy on the listening task. We also found that, with regard to comprehensibility, no specific artist or music genre appeared to be more comprehensible than the others. In terms of task difficulty, all but three participants rated the overall task difficulty at 5 (difficult), which suggests that comprehension of Spanish music lyrics is difficult in terms of L2 listening. One explanation for the nonsignificant correlation between task difficulty ratings and listening task scores may be the overall difficulty of the task. If the task were easier, a wider range of difficulty ratings may have been possible, thus allowing for a better analysis of the role of task difficulty in the comprehension of music. Nevertheless, the findings for task difficulty in this study suggest that the listening task was complex, and future studies would do well to compare performance on the listening task with performance on a less complex version of the task (cf. Baralt, 2010).

Vocabulary knowledge, on the other hand, was significantly correlated to listening task scores. In other words, learners who were more familiar and/or knowledgeable of specific words included in the vocabulary task were more likely to score higher on the listening task. This finding confirms previous research that has demonstrated a positive impact of vocabulary knowledge on L2 listening comprehension (e.g., Johnson, 1982; Schmidt, 2009). Nevertheless, most participants, regardless of their enrolled class level, were familiar with the majority of the words. This result suggests that vocabulary knowledge, though important in relation to accuracy on the listening task, may not have been the major hindrance given that most participants were, in fact, familiar with the words. 
In response to the second research question, which addresses the specific characteristics of music that predict accurate comprehension, our study demonstrated that items with dialectal features proved to be more difficult for learners to comprehend. This finding is in line with previous research that has demonstrated low accuracy in the comprehension, identification, or production of dialectal features by learners without experience in a particular dialect (e.g., Geeslin \& Gudmestad, 2011; Schmidt, 2009, 2011). Interestingly, learners comprehended one item with lateralization accurately and consistently, but not the other item with this same feature. On the basis of this finding, we recommend that future studies focus on a single dialectal feature (i.e. lateralization) in a number of differing contexts to better understand inconsistency in the comprehension of a particular dialectal feature.

The third and final research question guiding this study asked which learner characteristics predict accurate comprehension. First, 400-level learners consistently comprehended more items than the 300-level learners, although proficiency (as determined by an independent measure) did not significantly predict accuracy of listening comprehension. Other important factors included study abroad experience and frequency of listening to Spanish music: Learners who spent more time abroad and listened to Spanish music more frequently were more likely to have higher listening comprehension scores. These results suggest that learners with the most authentic input from multiple sources are likely to demonstrate more accurate comprehension of Spanish music. The learners' comprehension also complements the suggestion of incorporating music into the classroom made by Geeslin and Long (2014). Given that learners with more authentic input from more time spent were are more likely to have higher comprehension scores on the listening task, the same music could be introduced into the classroom as another source of authentic input. It is also worth noting that none of the learners from this study reported studying abroad in the Caribbean where they would have likely gained authentic exposure to the dialectal features under study.

Interestingly, all learners accurately comprehended one of the filler items (Item 38) on the listening task. The phrase of that lyric was tengo una vida loca "I have a crazy life," which is likely to be a very familiar phrase to learners. It may be that greater experience with or exposure to certain phrases may be more beneficial in the comprehension of L2 music than knowledge of individual words. Such experience may be particularly helpful when additional noise (in this case, the background music) is present in the speech signal. A recommendation for future studies would be to assess learners' familiarity with phrases or word pairs in addition to individual words in isolation to better understand listening comprehension of L2 music.

\section{Limitations}

There are several limitations of this study that are important to address and improve upon in future research. First, given that the speech samples included in the listening task were embedded in music, phonetic analysis of the music lyrics was not possible. Consequently, the researchers classified the dialectal features in each listening task item impressionistically. If possible, in future studies, researchers should attempt to separate the lyrics from the background music in order to more accurately identify dialectal features 
in the lyrics.

Second, our findings did not suggest a relationship between the distinct artists or genres represented in the listening task and accurate comprehension of music lyrics; rather, individual task items and word clusters had more of an effect on comprehension than any broad explanation of the comprehensibility of certain genres or artists. It is possible that the listening task could have been made easier (or more difficult) by either including simply one genre and/or artist. Because genre and artist were initially expected to be a factor in comprehension, information about the specific musical features of each clip of music was not included. For future studies, it would be useful to ask learner participants to indicate, along with the comprehensibility of each item, what it was about each music clip that made it easier or more difficult to understand than others. Another recommendation would be to include clips of native Spanish speakers (of Caribbean Spanish) reading the same words present in each clip in order to further understand learners' comprehension of the music lyrics. This methodological addition could further serve as a listening proficiency task, to clarify learners' abilities in the L2.

Finally, the present study examined comprehension of music by only two levels of learners. Although the results of this study did show that the 400-level learners outperformed the 300-level learners, there are more learner levels that would be interesting to investigate. Future studies should include more advanced learners (e.g., graduate students) and native speakers of Spanish to provide more insight into the development of comprehension of Spanish language music containing dialectal features.

\section{Conclusion}

The purpose of this study was to identify the difficulties students of Spanish face in their comprehension of music lyrics containing Caribbean Spanish dialectal features. This study addressed factors such as learner characteristics (i.e., reported time spent abroad, listening anxiety, proficiency), vocabulary knowledge, music genre (i.e., reggaeton, son, merengue), and Caribbean dialectal features (i.e., /d/ elision, /s/ aspiration). By investigating these factors, we contribute to multiple bodies of literature in second language acquisition and, importantly, show that comprehension of L2 music appears to be a difficult task for learners.

To conclude, we want to highlight the practical importance of the present study. Instructors would do well to include music in the L2 classroom for several reasons. First, as shown by participants' scores on the listening task and listening task difficulty ratings, Spanish music lyrics as a text type appears to be very difficult for learners. Incorporating Spanish language music in the classroom, along with guided instruction, may allow for improvement of L2 learners' listening comprehension. Second, using Spanish language music in the classroom is an authentic, creative way to introduce the inherent variation that learners will encounter in the L2 (Geeslin \& Long, 2014), without physically traveling to a Spanish speaking country. Further, just as students with more diverse, authentic sources of input (i.e., those who studied abroad, listened to Spanish music more often in the present study) scored higher on the listening task, students who listen to more music-and therefore receive more varied input-may be able to improve their listening skills in the L2 overall. Finally, incorporating Spanish language music in the classroom has the potential to 
act as a cultural bridge, providing common ground and interest for classroom learners and students who have the opportunity to study abroad in the future.

\section{References}

Auger, J. (2003). Linguistic norm vs. functional competence: Introducing Québec French to American students. In C. Blyth (Ed.), The sociolinguistics of foreign-language classrooms: Contributions of the native, the near-native, and the non-native speaker (pp. 79-104). Boston: Heinle.

Bacon, S. M. (1992). The Relationship between gender, comprehension, processing strategies, and cognitive and affective response in foreign language listening. The Modern Language Journal, 76(2), 160-178.

Baralt, M. (2010). Task complexity, the Cognition Hypothesis, and interaction in CMC and FTF environments (Unpublished doctoral dissertation). Georgetown University.

Bernhardt, E. B. (1991). A psycholinguistic perspective on second language literacy. AILA Review, 8, 31-44.

Call, M. E. (1985). Auditory short-term memory, listening comprehension, and the input hypothesis. TESOL Quarterly, 19(4), 765-781.

Canale, M., \& Swain, M. (1980). Theoretical bases of communicative approaches to second language teaching and testing. Applied Linguistics, 1(1), 1-47.

Carrier, K. (1999). The social environment of second language listening: Does status play a role in comprehension? The Modern Language Journal, 83, 65-79.

Conrad, L. (1989). The effects of time-compressed speech on native and EFL listening comprehension. Studies in Second Language Acquisition, 11(1), 1-16.

Diaz-Campos, M., Fafulas, S., \& Gradoville, M. (2012). Variable degrees of constituency: Frequency effects in the alternation of pa vs. para in spoken discourse. In K. Geeslin \& M. Díaz-Campos (Eds.), Selected proceedings of the 14th Hispanic Linguistics Symposium (pp. 75-87). Somerville, MA: Cascadilla Proceedings Project.

Eisenstein, M., \& Berkowitz, D. (1981). The effect of phonological variation on adult learner comprehension. Studies in Second Language Acquisition, 4(1), 75-80.

Elkhafaifi, H. (2005). Listening comprehension and anxiety in the Arabic language classroom. The Modern Language Journal, 89, 206-220.

Failoni, J. W. (1993). Music as means to enhance cultural awareness and literacy in the foreign language classroom. Mid-Atlantic Journal of Foreign Language Pedagogy, 1, 97-108.

Fujita, J. (1984). A preliminary inquiry into the successful and unsuccessful listening strategies of beginning college Japanese students (Unpublished doctoral dissertation). The Ohio State University.

Garfinkel, A. (1972). The enrichment-oriented radio program: A medium for building listening comprehension skills. Hispania, 55(2), 310-312. 
Geeslin, K. L. (Ed.). (2014). The handbook of Spanish second language acquisition. Malden, MA: Wiley-Blackwell.

Geeslin, K., \& Gudmestad, A. (2011). The acquisition of variation in second-language Spanish: An agenda for integrating studies of the L2 sound system. Journal of Applied Linguistics, 5(2), 137-157.

Geeslin, K. L., \& Long, A. Y. (2014). Sociolinguistics and second language acquisition: Learning to use language in context. New York: Routledge.

Guitar, J. M. (1997). Variability, multilectalism, and the organization of phonology in Caribbean Spanish dialects. In F. Martínez-Gil \& A. Morales-Front (Eds.), Issues in the phonology and morphology of the major Iberian languages (pp. 515-536). Washington, DC: Georgetown University Press.

Hammadou, J. (2000). The impact of analogy and content knowledge on reading comprehension: What helps, what hurts. The Modern Language Journal, 84(1), 3850.

Herron, C. A. (1991). The effect of authentic oral texts on student listening comprehension in the foreign language classroom. Foreign Language Annals, 24(6), 487-495.

Hualde, J. I. (2014). Los sonidos del español. Cambridge, UK: Cambridge University Press.

Johnson, P. (1982). Effects on reading comprehension of building background knowledge. TESOL Quarterly, 16(4), 503-516.

Major, R. C., Fitzmaurice, S. M., Bunta, F., \& Balasubramanian, C. (2005). Testing the effects of regional, ethnic, and international dialects of English on listening comprehension. Language Learning, 55(1), 37-69.

Rubin, J. (1994). A review of second language listening comprehension research. The Modern Language Journal, 78, 199-221.

Schmidt, L. B. (2009). The effect of dialect familiarity via a study abroad experience on L2 comprehension of Spanish. In J. Collentine et al. (Eds.), Selected proceedings of the 11th Hispanic Linguistics Symposium (pp. 143-154). Somerville, MA: Cascadilla Proceedings Project.

Schmidt, L. B. (2011). Acquisition of dialectal variation in a second language: L2 perception of aspiration of Spanish /s/ (Unpublished doctoral dissertation). Indiana University.

Schmidt-Rinehart, B. C. (1994). The effects of topic familiarity on second language listening comprehension. The Modern Language Journal, 78, 179-189.

Seright, L. (1985). Age and aural comprehension achievement in francophone adults learning English. TESOL Quarterly, 19(3), 455-473.

Shohamy, E., \& Ibar. O. (1991). Validation of listening comprehension tests: The effect of text and question type. Language Testing, 8(1), 23-40.

Wilcox, G. K. (1978). The effect of accent on listening comprehension: A Singapore study. ELT Journal, XXXII(2), 118-127. 
PAgE 56 COMPREHENSION OF SPANISH LANGUAGE Music

Yang, R.-L. (1993). A study of the communicative anxiety and self-esteem of Chinese students in relation to their oral and listening proficiency in English (Unpublished doctoral dissertation). University of Georgia. 


\section{Appendix A}

Listening Task Answer Sheet (English Translation)

\begin{tabular}{|c|c|c|c|c|c|c|}
\hline \multirow[b]{2}{*}{$\begin{array}{l}\text { WHAT YOU } \\
\text { HEARD }\end{array}$} & \multirow[b]{2}{*}{ TRANSLATION } & \multicolumn{5}{|c|}{$\begin{array}{l}\text { COMPREHENSIBLE? } \\
\text { (easy to understand) }\end{array}$} \\
\hline & & Easy & $\begin{array}{c}\text { Somewhat } \\
\text { easy }\end{array}$ & $\begin{array}{l}\text { Neither } \\
\text { easy nor } \\
\text { difficult }\end{array}$ & $\begin{array}{c}\text { Somewhat } \\
\text { difficult }\end{array}$ & Difficult \\
\hline$P$ & & $\square$ & $\square$ & $\square$ & $\square$ & $\square$ \\
\hline$P$ & & $\square$ & $\square$ & $\square$ & $\square$ & $\square$ \\
\hline$P$ & & $\square$ & $\square$ & $\square$ & $\square$ & $\square$ \\
\hline$P$ & & $\square$ & $\square$ & $\square$ & $\square$ & $\square$ \\
\hline $\mathrm{P}$ & & $\square$ & $\square$ & $\square$ & $\square$ & $\square$ \\
\hline 1 & & $\square$ & $\square$ & $\square$ & $\square$ & $\square$ \\
\hline 2 & & $\square$ & $\square$ & $\square$ & $\square$ & $\square$ \\
\hline 3 & & $\square$ & $\square$ & $\square$ & $\square$ & $\square$ \\
\hline 4 & & $\square$ & $\square$ & $\square$ & $\square$ & $\square$ \\
\hline 5 & & $\square$ & $\square$ & $\square$ & $\square$ & $\square$ \\
\hline 6 & & $\square$ & $\square$ & $\square$ & $\square$ & $\square$ \\
\hline 7 & & $\square$ & $\square$ & $\square$ & $\square$ & $\square$ \\
\hline 8 & & $\square$ & $\square$ & $\square$ & $\square$ & $\square$ \\
\hline 9 & & $\square$ & $\square$ & $\square$ & $\square$ & $\square$ \\
\hline
\end{tabular}




\section{Appendix B}

\section{Vocabulary Task Words and Translations}

\begin{tabular}{lc}
\hline Word & Translation \\
\hline Aflojar & To lessen, reduce \\
Velocidad & Speed \\
Cáscara & Shell, peel \\
Rimas & Rhymes \\
Enfrentarse & To confront \\
Compadre & Buddy, friend \\
Atrasado & Late, behind \\
Sencillo & Simple \\
Asfixiado & Suffocated; overwhelmed \\
Merengue & Merengue (music genre) \\
Heridas & Wounds \\
Cintura & Waist \\
Voltear & To turn around \\
Pegado & Close, stuck \\
Pared & Wall \\
Reposo & Rest \\
Puerco & Pig \\
Monte & Mountain, hill \\
Botado & Good-for-nothing, useless \\
\hline & \\
\hline &
\end{tabular}

\section{Appendix C}

\section{Spanish Proficiency Test (Sample)}

Creo que es muy interesante (hablo / hablar / hablando) de los hábitos de la gente.

Yo, por mi parte, __ (soy / estoy / tengo) vegetariana.

Translation: "I think it is very interesting to talk about people's eating habits. I, for my part, am vegetarian." 


\section{Appendix D \\ Listening Anxiety Questionnaire}

Participants were instructed to complete these items using the following scale: $1=$ strongly disagree, $2=$ disagree, $3=$ neither agree nor disagree, $4=$ agree, $5=$ strongly agree .

1. I get upset when I'm not sure whether I understand what I'm hearing in Spanish.

2. When I listen to Spanish, I often understand words but still can't quite understand what the speaker is saying.

3. When I'm listening to Spanish, I get so confused I can't remember what I've heard.

4. I feel intimidated whenever I have a listening passage in Spanish to listen to.

5. I am nervous when I am listening to a passage in Spanish when I'm not familiar with the topic.

6. I get upset whenever I hear unknown grammar while listening to Spanish.

7. I usually end up translating word by word when I'm listening to Spanish.

8. By the time you get past the unfamiliar sounds in Spanish, it's hard to remember what you're listening to.

9. I am worried about the new sounds you have to learn to understand spoken Spanish.

10. I enjoy listening to Spanish.

11. I feel confident when I am listening to Spanish.

12. Once you get used to it, listening to Spanish is not so difficult.

13. The hardest part of learning Spanish is learning to understand spoken Spanish.

14. I would be happy just to learn to read Spanish rather than having to learn to understand spoken Spanish.

15. I don't mind listening to Spanish by myself but I feel very uncomfortable when I have to listen to Spanish in a group.

16. I am satisfied with the level of listening comprehension in Spanish that I have achieved so far.

17. Spanish culture and ideas seem very foreign to me.

18. You have to know about Spanish history and culture in order to understand 